DISTRIBUTION STATEMENT A. Approved for public release; distribution is unlimited.

\title{
Effect of Broadband Nature of Marine Mammal Echolocation Clicks on Click-Based Population Density Estimates
}

\author{
Michael Ainslie \\ PO Box 96864 \\ $2509 \mathrm{JG}$ \\ The Hague, The Netherlands \\ phone: +31 888669099 fax:+31888666575 email: michael.ainslie@tno.nl
}

Award Number: N000141410409

https://www.tno.nl/

\section{LONG-TERM GOALS}

The long-term aim of the project is to support passive acoustic monitoring (PAM) of Odontecetes.

\section{OBJECTIVES}

This project aims to demonstrate how the detection process of broadband clicks can be modeled for different marine mammal species and assess the magnitude of error on the estimated density due to various commonly used simplifying assumptions. Our main purposes are to quantify the bias in the population density estimate for selected species and detector due to use of the narrow band approximation in the computed propagation loss, and to understand the factors affecting the magnitude of this bias to enable extrapolation to other species and detectors.

\section{APPROACH}

Key individuals at TNO: Ainslie, von Benda-Beckmann

Key individuals at University of St Andrews: Thomas (CREEM), Tyack (SMRU)

Technical approach:

This project is in collaboration between TNO (PI: Michael Ainslie) with the University of St. Andrews (grant number: N000141410396, PI: Len Thomas).

Detectability of a broadband echolocation click is quantified by synthesizing pressure time series separately for noise $f_{N}(t)$, signal $f_{S}(t ; r)$, and signal plus noise $f_{S+N}(t ; r)=f_{S}(t ; r)+f_{N}(t)$ (as illustrated in Figure 1). As a basis for the source echolocation clicks we intend to use recordings of echolocation clicks obtained nearby to the species considered in this study. These recorded source clicks are used to synthesize the corresponding echolocation clicks at the different ranges of interest, accounting for the effects of frequency dependent absorption on both propagation loss and detector performance. The resulting modeled received signal + noise are then fed through various detectors, thus enabling a highfidelity estimation of the detection probability without recourse to the sonar equation. The detection probability will be established by repeating the process for multiple realizations of the noise. 


\section{Report Documentation Page}

Form Approved

OMB No. 0704-0188

Public reporting burden for the collection of information is estimated to average 1 hour per response, including the time for reviewing instructions, searching existing data sources, gathering and maintaining the data needed, and completing and reviewing the collection of information. Send comments regarding this burden estimate or any other aspect of this collection of information,

including suggestions for reducing this burden, to Washington Headquarters Services, Directorate for Information Operations and Reports, 1215 Jefferson Davis Highway, Suite 1204, Arlington

VA 22202-4302. Respondents should be aware that notwithstanding any other provision of law, no person shall be subject to a penalty for failing to comply with a collection of information if it

does not display a currently valid OMB control number.

1. REPORT DATE

30 SEP 2014

4. TITLE AND SUBTITLE

Effect of Broadband Nature of Marine Mammal Echolocation Clicks on Click-Based Population Density Estimates

6. AUTHOR(S)

7. PERFORMING ORGANIZATION NAME(S) AND ADDRESS(ES)

TNO,PO Box 96864,2509 JG,The Hague, The Netherlands,

9. SPONSORING/MONITORING AGENCY NAME(S) AND ADDRESS(ES)

12. DISTRIBUTION/AVAILABILITY STATEMENT

Approved for public release; distribution unlimited

13. SUPPLEMENTARY NOTES

14. ABSTRACT

15. SUBJECT TERMS

16. SECURITY CLASSIFICATION OF:

a. REPORT

unclassified b. ABSTRACT

unclassified c. THIS PAGE

unclassified
17. LIMITATION OF ABSTRACT

Same as Report (SAR)
3. DATES COVERED

00-00-2014 to 00-00-2014

5a. CONTRACT NUMBER

5b. GRANT NUMBER

5c. PROGRAM ELEMENT NUMBER

5d. PROJECT NUMBER

5e. TASK NUMBER

5f. WORK UNIT NUMBER

8. PERFORMING ORGANIZATION REPORT NUMBER

10. SPONSOR/MONITOR'S ACRONYM(S)

11. SPONSOR/MONITOR'S REPORT NUMBER(S) 


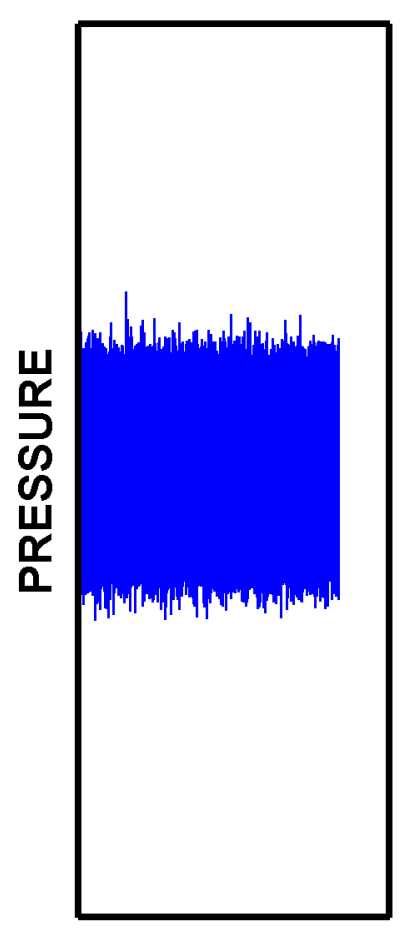

TIME

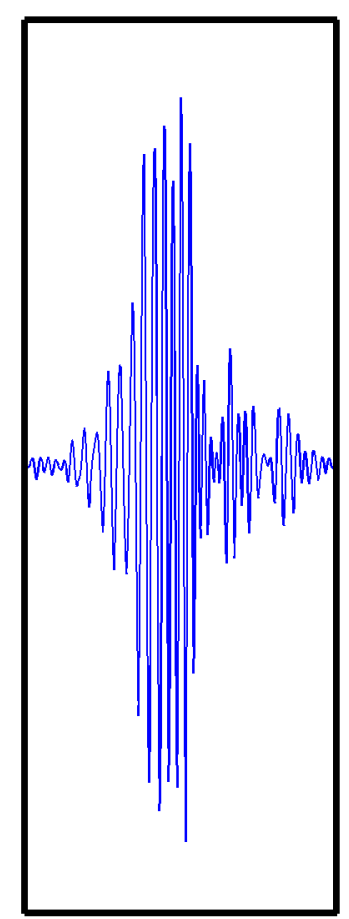

TIME

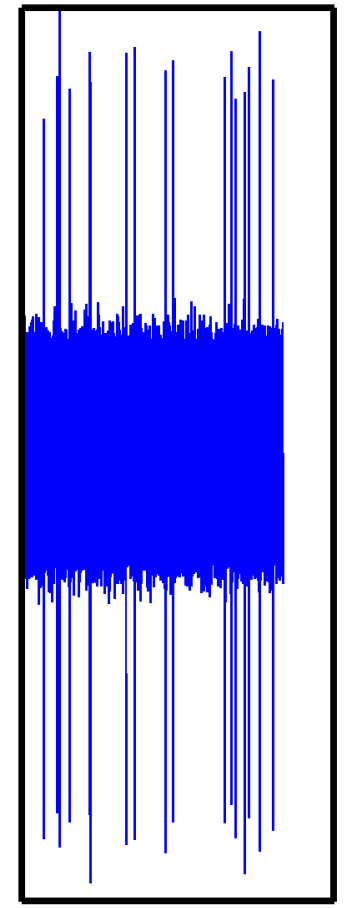

TIME

Figure 1 : Illustration of modeling procedure for generating test data for. Simulated echolocation clicks are generated through a Monte-Carlo approach by mixing recorded noise segments (left) with a synthesized signal waveform, which was propagated from near the source to a particular distance of the detector. The simulated test datasets are then run through various click detection algorithm to

assess the detection probability and potential biases due to different propagation assumptions.

In this study we simulate the received click in the time domain for various echolocating marine mammal species. The research will focus initially on beaked whales (Blainville's or Cuvier's), for which high quality click recordings of clicks are available from DTAG data, as these are known to be sensitive to sonar sound, in a few cases leading to mass stranding, and therefore of high relevance to the US Navy. The same methodology will be applied also to other species such as sperm whale (Physeter macrocephalus) (whose high source level assures long range detection and amplifies broadband effects) and bottlenose dolphins (Tursiops truncatus) as a representative of a delphinid species with large bandwidth echolocation clicks.

The magnitude of the error caused by applying the conventional approach can be established at this stage by comparing detection probability computed for a broadband pulse with the approximation obtained with $\mathrm{PL}_{\mathrm{NB}}$. The magnitude of the density estimation errors due to various simplifications using the passive sonar equation will be compared to other uncertainties introduced by variations in, e.g., click rate, group size, and click directionality.

\section{WORK COMPLETED}

The project kick-off meeting was held in July 2014. 
Progress to date includes:

- $\quad$ reschedule project due to delayed start (new end date $=$ April 1, 2015)

- $\quad$ approach various dataholders and collate suitable source click data

- inventorize common PAM detection algorithms

- $\quad$ adapt Matlab simulation platform used in von Benda-Beckmann et al. (2010) to work with various source signals and detectors.

- present progress at ESOMM 2014, Amsterdam (September 11, 2014)

\section{RESULTS}

There are no significant results to report from the first three months of this study. An inventory of common PAM detection algorithms to be considered as representative detection models are listed in Table 1.

Table 1 : Inventory of common detection algorithms used in PAM applications for detecting marine mammal echolocation clicks.

\begin{tabular}{|l|l|}
\hline Detector & Reference \\
\hline Pamguard Click detector & Gillespie and Leaper (1995) \\
\hline FFT energy band detector & Ward et al. (2008) \\
\hline Power-Law Page test detector & Van IJsselmuide and Beerens (2004) \\
\hline Matched-filter detector & Ward et al. (2008) \\
\hline Teager-Kaiser (TK) click detector & Kandia and Stylianou (2005) \\
\hline Ishmael energy sum click detector & Yack et al. (2010), Mellinger (2001) \\
\hline Energy Ratio mapping & Klinck and Mellinger (2011) \\
\hline
\end{tabular}

\section{IMPACT/APPLICATIONS}

Estimates for the abundance of marine mammals are required for the assessment and effective mitigation of the impact of naval activities, such as sonar or underwater detonations, on marine mammals. Obtaining reliable and unbiased abundance estimations of marine mammals is essential, because in environmental impact assessments a bias would cause an under- or over-estimate of the number of marine mammals affected by naval activities.

The proposed study will result in guidance on the species and conditions for which a simplified use of the passive sonar equation can be used to obtain unbiased population density estimation, or for which more elaborate and time-consuming modeling of the click propagation and detection is required. Such guidelines could then be used for ongoing and future PAM projects that rely on detection of broadband echolocation clicks.

It is expected that the method developed in the proposed study will improve the accuracy of marine mammal density estimation based on counting echolocation clicks, and will be applicable to density estimates obtained using different PAM-approaches, including bottom-mounted/ deployed hydrophones and line transect surveys. 


\section{RELATED PROJECTS}

Effect of broadband nature of marine mammal echolocation clicks on click-based population density estimates (grant number: N000141410396, PI: Len Thomas, University of St. Andrews).

\section{REFERENCES}

Gillespie, D. and Leaper, R. (1996). Detection of sperm whale Physeter macrocephalus clicks and discrimination of individual vocalizations. European Cetacean Research. Abstracts, pp. 10:87-91.

Kandia, V., and Stylianou, Y. (2005). Detection of sperm whale clicks based on the Teager-Kaiser energy operator, Applied Acoustics, 67: 1144-1163.

Mellinger, D.K. (2001) Ishmael 1.0 user's guide, NOAA Technical Memorandum OAR PMEL.

Klinck, H. and Mellinger, D.K. 2011, 'The energy ratio mapping algorithm: A tool to improve the energy-based detection of odontocete echolocation clicks', The Journal

van IJsselmuide, S.P. and Beerens, S.P. (2004). Detection and classification of marine mammals using an LFAS array. Canadian Acousics 32, 4.

von Benda-Beckmann A.M., Lam F.P.A., Moretti D.J., Fulkerson K., Ainslie M.A., van IJsselmuide S.P., Theriault J., and Beerens S.P. (2010). Detection of Blainville's beaked whales with towed arrays. Applied Acoustics 71:1027-1035.

Ward, J.A., Thomas, L., Jarvis, S., DiMarzio, N., Moretti, D., Marques, T.A., Dunn, C., Claridge, D., Hartvig, E. and Tyack, P. (2008). Passive acoustic detection and localization of Mesoplodon Densirostris (Blainville's beaked whale) vocalizations using distributed bottommounted hydrophones in conjunction with a digital tag (DTag) recording, Canadian Acoustics, 36 (1):6066.

Yack, T.M., Barlow, J., Roch, M.A., Klinck, H., Martin, S., Mellinger, D.K. \& Gillespie, D. 2010 , 'Comparison of beaked whale detection algorithms', Applied Acoustics, vol. 71, no. 11, pp. 10439. 